Girado, J. N. \& CAmpbell, J. B. (1959). The innervation of the urethra of female cat. Expl Neurol. I, 44.

GreEne, L. F. \& EmMETt, J. L. (1963). Physiology of the normal bladder ; neurophysiology of micturition, In Urology, Vol I, Ed. Meredith Campbell, 2nd ed. Philadelphia : Saunders.

Gyermek, L. (I96I). Cholinergic stimulation and blockade on urinary baldder. Am. $\mathcal{F}$. Physiol. 201, 325.

Hukovic, S., Rand, M. J. \& Vanov, S. (1965). Observations on an isolated innervated preparation of rat urinary bladder. Br. F. Pharmac. Chemother. 24, I78.

INNES, I. R. \& NICKERSON, M. (I965). Drugs acting on post-ganglia adrenergic nerve endings and structures innervated by them (sympathomimetic drugs). In The Pharmacological Basis of Therapeutics, Chap. 24, Ed. Goodman, L. F. \& Gilman, A. New York: MacMillan.

Kuntz, A. (1953). Innervation of the urinary organs. In The Autonomic Nervous System, p. 269. Philadelphia : Lea and Febiger.

Kuru, Masaru (1965). Nervous control of micturition. Physiol. Rev. 45, 426.

LEARMONTH, J. (I93I). A contribution to the neurophysiology of the urinary bladder in man. Brain, 54, I 47.

Perlmutter, A. (1967). Long term effects on unilateral vesical denervation in a canine bifid bladder preparation. Invest. Urol. 4, 539.

SIGG, E. B. \& SIGG, T. D. (I964). Sympathetic stimulation and blockade of the urinary bladder in the cat. Int. F. Neuropharmac. 3, 24I.

Tanagho, E. A. \& Smith, D. R. (I966). The anatomy and function of the bladder neck. Br. F. Urol. 33, 54.

Tanagho, E. A., Miller, E., Meyers, F. \& Corbett, R. K. (I966). Observations on the dynamics of the bladder neck. Br. F. Urol. 33, 72.

URsillo, R. C. (I96I). Electrical activity of the isolated nerve urinary bladder strip preparation of the rabbit. Am. F. Physiol. 201, 408.

Winter, D. L., Henson, C. \& Caggiano, V. (I966). Firing patterns of urinary bladder receptors. Fedn. Proc. Fedn Am. Socs exp. Biol. Physiology abstract No. 789.

ZiNNER, N. \& RitTER, R. (I967). Bladder physiology. In The Neurogenic Bladder, pp. I8-3I, Ed. Boyarsky, S. Baltimore: Williams and Wilkins.

\title{
THE NEUROGENIC BLADDER OF NON-TRAUMATIC ORIGIN
}

\author{
By M. Damanski, M.D., F.R.C.S.
}

A FEW years ago, when working in a Paraplegic Centre, I was one of the contributors to two papers on the 'Neurogenic Bladder of Non-Traumatic Origin' (Damanski and Kerr, I964; Ross, Gibbon and Damanski, I964). In the years which followed I had a new opportunity of working in several departments for long-stay and geriatric patients. It was only then that I realised that our previous presentation of the subject was somewhat one-sided, as it was dealing mainly with the patients who needed surgical operations. When invited to write this paper I decided to give a more complete picture by including those who suffer from the so-called 'geriatric bladder'.

Generally speaking, there are diseases notorious for bladder dysfunction, such as disseminated sclerosis, tabes dorsalis and spina bifida. (I must mention that the latter is not included in the scope of this lecture.) These patients constitute a numerous group among those admitted to hospitals and are comparatively well studied. On the other hand, there are interesting selective diseases, such as subacute combined degeneration of the spinal cord and motor-neurone disease which are accompanied by bladder dysfunction at one stage or another, the nature of which has not been investigated so far. 


\section{TRANSVERSE SPINAL LESION}

The best known clinical syndrome is a transverse spinal lesion giving rise to the classical pattern of paraplegic bladder. Here is a brief list of the underlying pathological causes:

\section{Intradural, intramedullary}

(a) Haematomyelia (spontaneous), due to bleeding from a vascular malformation, such as angioma or telangiectasis, or following treatment with anticoagulants.

(b) Thrombosis of the anterior spinal artery of unknown origin, or due to a dissecting aneurism of the aorta or arteriosclerosis of a spinal artery arising from it.

(c) Infective or post-vaccinal myelitis.

(d) Advanced syringomyelia.

(e) Glioma.

(f) Syphilitic meningo-myelitis.

\section{Intradural, extramedullary}

(a) Meningitis, pyogenic or tuberculous.

(b) Chronic arachnoiditis.

(c) Meningioma, neurofibroma and cholesteatoma.

(d) Infiltration of the meninges in carcinomatosis, myelomatosis and Hodgkin's disease.

\section{Extradural}

(a) Acute and chronic extradural infection.

(b) Syphilitic granuloma.

(c) Diseases of the vertebral column, like spondylosis, displaced disc, tuberculous caries, Paget's osteitis, collapse of a vertebra due to senile osteoporosis, secondary carcinoma from the breast, prostate or other organs.

\section{DISTURBED BLADDER PHYSIOLOGY}

It would go far beyond the scope of this paper to quote all the views on this interesting subject, which has already been dealt with in previous papers in this symposium. There are numerous supraspinal micturition centres and a lower sacral one. The upper centres account for facilitation, inhibition and co-ordination. A complete, transverse lesion of the cord distal to the mid-pontine level, brings about a release of the sacral centres from the supraspinal mechanism and, in man, a temporary depression of its activity, perhaps due to a sudden loss of the descending, facilitatory impulses. This stage has been called 'spinal shock' (Marshall Hall, I84I). After a variable time recovery and later hyperactivity of the reflexes takes place, the uninhibited bladder reflex being one of them.

In an incomplete, transverse lesion there may be a variable degree of dysfunction ranging from an impaired appreciation of fullness or inhibition to an almost complete loss of sensory appreciation and volitional control. 
In the case of a lesion of the spinal reflex centres in the conus medullaris and/or the nerve-roots, there is a permanent loss of reflex activity but in some cases the bladder can be emptied by abdominal straining and manual expression.

\section{BLADDER DYSFUNCTION IN SOME COMMON NEUROLOGICAL DISEASES}

I. Disseminated Sclerosis. Urinary symptoms presenting as one of the initial features of the disease constitute 5 per cent. in Muller's series (I949), 3 per cent. in the cases quoted by Adam et al. (1950), 4 per cent. in McAlpine's et al. series (1955) and $2 \frac{1}{2}$ per cent. in Poser's group (I966). McAlpine (I955) recorded a 23-year-old male patient whose acute retention was an early feature of the disease in the absence of other significant neurological signs.

Poser et al. (1966) found that bladder dysfunction in the advanced stage of the disease occurred in 82 per cent. of their patients and Bradley's et al. figures, 80 per cent., were similar (1967).

The exact nature of dysfunction is as follows:

I. In the initial stage there is an overactive bladder with a low threshold of the micturition reflex and an impaired volitional control, that is uninhibited incontinence. In some cases there are sensory changes involving the sacral segments associated with an impaired appreciation of bladder filling and a tendency to retention.

2. In a more advanced stage there may be the clinical features of a transverse cord lesion, a typical paraplegic bladder with overflow incontinence. It is found that these patients need more urological care than those due to trauma, the possible reason being increased tonus of the external sphincter, as noted by Bradley et al. (1967).

3. Infection, spontaneous or catheter-induced, is a common complication and has been established as a direct cause of death, by Reinhold (I950) in 2I per cent. of patients and by Zimmermann and Netsby (1950) in 40 per cent.

2. Tabes Dorsalis and Diabetes Mellitus. In these two diseases there is a selective degeneration of the posterior roots of the spinal nerves and of the posterior columns of the cord. Appreciation of bladder fullness is impaired or abolished, this in turn leading to distension with a high residual urine and infection.

In tabes, bladder dysfunction is reported in approximately 50 to 60 per cent. of patients. In diabetes its incidence must be comparatively rare, as only occasionally these patients are referred to urological departments. Diabetic neuropathy as it affects the bladder has been described in detail by several authors (Gill, 1936; Rudy and Muellner, I94I; Hopkins and Pierce, I967).

3. Bladder Dysfunction of Geriatric Patients. Until recently the geriatric bladder received little attention. In the last decade, however, many specialised departments have been opened for these patients, and their urinary incontinence has become a major problem from the medical and nursing points of view. As most women outlive men, and more of them reach the state of senility, they constitute about three-quarters of the patients on the geriatric wards and are the most numerous group of patients with neurogenic bladder. 
The dysfunction is due primarily to the lesion of the micturition centres in the brain (Andrew and Nathan, 1964), and in many cases is associated with or aggravated by dementia.

A comprehensive study of the geriatric bladder was undertaken by Brocklehurst and Dillane $(1967 a, b)$.

In the first place investigations were carried out on 40 elderly, continent female patients. Only I5 per cent. of them had normal cystometric findings. Many of the remaining had a bladder capacity considerably reduced to 200 to $250 \mathrm{ml}$., and at this level the desire to void was appreciated but could not be restrained and uninhibited contraction took place with a leak around the catheter. In other words, there was a small bladder with insufficient warning between the desire to micturate and the act of micturition. Bladder dysfunction was most marked in patients with right hemiparesis, which is a lesion of the left dominant hemisphere.

Residual urine from 25 to $100 \mathrm{ml}$. was found in all patients. Also other writers (Ruikka, 1963; Sourander et al., 1965) report residual urine as a constant feature.

Later they investigated a group of 100 incontinent females. In this series the bladder capacity was still smaller and the residual urine higher, uninhibited contractions occurring in many more patients than in the first group. Again, those with right hemiparesis were most seriously affected.

Urinary infection has been reported in about 50 per cent. of the aged, female patients (Parvinen et al., I965; Sourander et al., I965), often correlated to cystocele caused by laxity of the vaginal wall or uterine prolapse. Parvinen et al. (1965) report vesico-ureteric reflux in Io per cent. of the infected patients.

\section{TREATMENT}

Acute Retention. Patients with an acute onset of neurological lesion present an acute retention of urine. Care should be taken not to mistake it for prostatic obstruction and I know of two patients with acute neurogenic bladder who were unnecessarily submitted to prostatectomy.

Short-lasting retention is treated by intermittent catheterisation. Cholinergic drugs sensitise the reflex activity of the detrusor and can be tried first. Bethanechol Chloride (Urecholine Chloride, Merck and Dohme), is not destroyed by cholinesterase and less toxic than Carbachol. The recommended oral or sublingual dose is 10 to $30 \mathrm{mg}$. three or four times daily. The drug should never be given intravenously or intramuscularly as it might result in cardiac arrest. In patients who do not respond to oral therapy it can be given subcutaneously, beginning with a dose of $2.5 \mathrm{mg}$. $(0.5 \mathrm{ml}$.), and following this with a second, third or fourth similar dose at 15 to 30 -minute intervals if neither satisfactory response nor disturbing side-effects result.

Chronic Retention. In many patients bladder dysfunction appears slowly and overflow incontinence develops. Urine dribbles away or is ejected in small spurts on any increase of the intra-abdominal pressure, such as change of position, coughing, laughing, etc. It is essential to catheterise these patients for residual urine immediately following the latest voiding, as suprapubic palpation and percussion may be misleading. 
In chronic retention the bladder should be drained with an indwelling catheter of Gibbon type (Gibbon, 1958, I96I), or an intermittent catheter if the latter is the preference of those in charge. In the case of a permanent and non-progressive lesion of the cord above the sacral reflex arc an uninhibited reflex bladder is anticipated. In the case of a lesion involving the sacral reflex arc an expressible bladder is the aim. Persistent residual urine and infection have to be eliminated or reduced by an appropriate surgical procedure based on the cystourethrographic studies (Damanski and Kerr, I957; Damanski, I96I, I965). The most frequently performed remedial operations on the bladder outlet are trans-urethral resection (T.U.R.) introduced into paraplegia by Emmett (1945) and division of the external sphincter (D.E.S.) devised by Cosbie Ross (Ross et al., 1956, 1958, 1963, I967).

Overflow Incontinence from Loss of Sensation. Tabes and diabetes are the commonest diseases in which this condition occurs. Such patients do not empty their bladders efficiently as they have no desire to micturate. Only after they have been instructed to empty their bladders at regular intervals, is their incontinence controlled, always provided the detrusor has not been overstretched beyond recovery.

Incontinence from Uninhibited Bladder. This term is applied to the patients with a selective lesion of the efferent neurone (McLellan, I939). They have appreciation of a full bladder but are unable to inhibit micturition. The patient must remember to empty his bladder at regular intervals to prevent the critical filling at which an uninhibited emptying reflex is elicited. This method has been called 'bladder training' by Munro (1947). Some patients may prefer a portable urinal which makes them more independent from their régime and helps to avoid embarrassing situations.

Overactivity Incontinence. This type of incontinence differs only in degree from the uninhibited bladder and is encountered in some brain lesions, the geriatric bladder being the most frequent, but some patients with disseminated sclerosis are included in the same group. The threshold of reflex activity is lowered and inhibition impaired, so that micturition takes place at short intervals from a bladder filled only to a part of its anatomical capacity.

It is a comparatively easy task to make these patients micturate at short intervals during the day but their incontinence becomes a major problem at night. Constipation is an aggravating factor and should be avoided. In male patients the well-known urinals are difficult to apply when the penis is short and often impossible to keep in position when a patient, whose intellectual capacity is failing, does not co-operate. Women cannot be fitted with a urine-tight appliance and incontinence pads fixed by plastic pants are the only workable solution.

Indwelling catheters are to be avoided as they result in infection and are indicated only in patients who have developed pressure sores owing to maceration of the skin by urine and faeces.

Restricted fluid intake in the evening is an effective preventive measure in young patients whose curve of water excretion is steep and when much of the ingested fluid can be eliminated before sleep. This is not the case in geriatric patients whose kidneys are not so efficient as there may be nocturnal polyuria due to chronic pyelonephritis. 
Posterior pituitary extract taken either as snuff (Piton, Organon, Di-Sipidin, Paines and Byrne) or injection (Vasopressin Tannate, oily suspension, 5 I.U., at bedtime and midnight) brings about oliguria, but its action is short-lived, about two to three hours. Meikle (I959) and Dequeker (1965) found it effective only in co-operative patients. Slotnik and Teigland (I95I) and Wakin, Denton and Essex (1954) have warned that injections may precipitate cardiac accidents.

The threshold of detrusor activity is reported to be raised and bladder capacity increased by the modern anticholinergic drugs. In the U.S.A. Methanteline Bromide (Banthine) is used in the average dose $50 \mathrm{mg}$. before meals, t.d.s. and Ioo mg. on retiring (there are also 50-mg. injections). In this country preference is given to Propantheline Bromide (Pro-Banthine Searle \& Co.) which is more potent and exhibits less severe side-effects. The average dose is I 5 mg., t.d.s., with meals and $30 \mathrm{mg}$. at bedtime (injections $30 \mathrm{mg}$. i.m. or i.v.). The most common side-effects are dizziness, dry mouth (xerostomia), tachycardia, constipation, postural hypotension and blurred vision. Contra-indications include pyloric stenosis, prostatic enlargement and glaucoma. Dequeker (1965) has found it ineffective in his series of 27 patients.

As to the other drugs, Imipramin (Tofranil) has been tried with some success in senile incontinence by Aarouson and Boger (1962). Atropine has been found by Ursillo (1967) to have no effect whatever on the bladder detrusor.

\section{SUMMARY}

I. The normal act of micturition is a motor activity of the detrusor activated by the sacral parasympathetic reflex centres. There are also higher micturition centres accounting for facilitation, inhibition and co-ordination.

2. A lesion of the micturition centres and/or their pathways results in bladder dysfunction known as 'neurogenic bladder'.

3. The best studied type of neurogenic bladder is that resulting from a transverse spinal lesion.

4. In the case of a complete lesion of the cord uninhibited reflex activity of the bladder can be anticipated, after a variable period of retention. In the event of a lesion of the sacral cord or its nerve roots the loss of reflex activity of the bladder is permanent but urine may be expressed by abdominal straining. In both types of dysfunction corrective surgical procedures may be needed to achieve complete bladder emptying and eliminate infection.

5. Disseminated sclerosis is usually accompanied by bladder dysfunction, overactivity in the early stage and retention later.

6. Tabes and diabetes are selective lesions of the afferent neurone presenting impairment of the desire to micturate. Micturition at frequent intervals should be encouraged.

7. There are other selective diseases of the nervous system with bladder dysfunction which have not yet been fully investigated.

8. A selective lesion of the efferent neurone brings about impaired or abolished inhibition. Frequent micturition (bladder training) is recommended to avoid critical filling.

9. In some senile patients cerebral function is upset by vascular lesions. As a result of this, incontinence develops from a small and over-active bladder, known as 'geriatric bladder'. There may also be impaired intellectual capacity, often with 
restlessness, confusional states or depression which makes co-operation difficult. The geriatric bladder is a serious medical and nursing problem and may best be controlled by frequent placing of the patient on a toilet, commode or bedpan, day and night. Anticholinergic drugs, Vasopressin and Imipramine may reduce frequency and control incontinence in some cases.

\section{REFERENCES}

Aarouson, H. G. \& Boger, W. P. (1962). Incontinence in the elderly : an attempt at control. F. Am. Geriat. Soc. 10, 626.

Adams, D. K., Sutherland, J. M. \& Fletcher, W. B. (1950). Early clinical manifestation of disseminated sclerosis. Br. med. F. 2, $43 \mathrm{I}$.

ANDREW, J. \& NATHAN, P. W. (I964). Lesion of the anterior frontal lobes and disturbances of micturition and defaecation. Brain, 87, 223.

Bradley, W. E., Markland, G. \& ChOU, S. (1967). Neurologic dysfunction of the urinary bladder in demyelinating disease of the central nervous system. In Neurogenic Bladder, ed. Boyarsky, S., pp. I58-I64. Baltimore: Williams and Wilkins.

Brocklehurst, J. C. \& Dillane, J. B. (1967a). Studies of the female bladder in old age. I. Cystometrograms in non-continent women. Geront. clin. 8, 285.

Brocklehurst, J. C. \& Dillane, J. B. (1967b). Studies of the female bladder in old age. II. Cystometrograms in 100 incontinent women. Geront. Clin. 8, 306.

DAMANSKI, M. (I96I). Cysto-urethrography in paraplegia: its practical application. Br. F. Urol. 33, 67.

DAMANSKI, M. (1965). Cysto-urethrography in paraplegia as a guide to catheter-free life. F. Urol. 93, 466.

DAMANSKI, M. \& KeRR, A. S. (1957). The value of cysto-urethrography in paraplegia. Br. F. Surg. 44, 398.

DAMANSKI, M. \& KERR, A. S. (1964). Paraplegia of non-traumatic origin and disseminated (Multiple) sclerosis : urinary complications, their nature and treatment. Acta neurol. psychiat. belg. 64, 495 .

DeQUEKER, J. (I965). Drug treatment of urinary incontinence in the elderly. Controlled trial with vasopressin and propantheline bromide. Geront. clin. 7, 3I I.

EMmETT, J. L. (I945). Urinary retention from imbalance of detrusor and vesical neck. Treatment by transurethral resection. F. Urol. 43, 692.

Gibbon, N. (1968). A new type of catheter for urethral drainage of the bladder. $B r . \mathcal{F}$. Urol. 30, I.

Gibbon, N. (I96I). Some recent developments in bladder drainage. F. Roy. Coll. Surg. Edinb. 6, 215.

GILL, R. (1936). The diabetic bladder. F. Urol. 36, 730.

Hall, Marshall (I84I). On the Diseases of the Nervous System. London: Baillière.

Hopkins, W. F. \& PIERCE, J. M. (I967). The neurogenic bladder in diabetes mellitus. In Neurogenic Bladder, ed. Boyarsky, S., pp. I55-I 57. Baltimore: Williams and Wilkins.

McAlpine, D., Compston, N. D. \& Lumsden, C. E. (I955). Multiple Sclerosis. Edinburgh : Livingstone.

McLellan, F. C. (1939). The Neurogenic Bladder. Springfield, Illinois: Thomas.

Meikle, R. W. (I959). Treatment of nocturia in the elderly with posterior pituitary snuff. F. Am. Geriat. Soc. 7, 422.

Muller, R. (1949). Studies in disseminated sclerosis. Acta med. scand. Suppl. 222.

MunRo, D. (1947). The rehabilitation of patients totally paralysed below the waist, with special reference to making them ambulatory and capable of earning their living. III. Tidal drainage, cystometry and bladder training. New Engl. F. Med. 236, 223.

Parvinen, M., Sourander, L. B. \& Vuorinen, P. (1965). Cystographic studies of old women. Geront. clin. 7, 343.

Poser, C. M., Presthus, J. \& Horschel, O. (1966). Clinical characteristics of autopsyproved multiple sclerosis. Neurology, Minneap. 16, 791.

Reinhold, M. (1950). Prognosis in disseminated sclerosis. Br. med. F. I, I60.

Ross, T. C. (1956). Br. F. Urol. 28, I4.

Ross, J. C., DAMANSKI, M. \& GIBBON, N. (1958). Resection of the external sphincter in the paraplegic-preliminary report. f. Urol. 73, 742. 
Ross, J. C., Gibbon, N. \& Damanski, M. (1963). Further experiences with division of the external urethral sphincter in paraplegia. f. Urol. 89, 692.

Ross, J. C., GibBon, N. O. K. \& DAMANSKI, M. (1964). Bladder dysfunction in non-traumatic paraplegia. Lancet, $\mathbf{I}, 779$.

Ross, J. C., Gibbon, N. O. K. \& Damanski, M. (1967). Division of the external sphincter in the treatment of the neurogenic bladder. A ten-year review. Br. F. Surg. 54, 627.

Rudy, A. \& Muellner, S. R. (I94I). The neurogenic bladder in diabetes mellitus. $\mathcal{F}$. Urol. 45,844 .

RuikKa, I. (1963). Residual urine in aged women and its influence on the phenolsulfonphthalein excretion test. Geront. clin. 5, 65.

SLotNIK, I. L. \& TEIGLAND, J. D. (I95I). Cardiac accidents following vasopressin injection. F. Am. med. Ass. 146, I 126.

SOURANDER, L. B., RUIKKA, I. \& Gronroos, M. (1965). Correlation between urinary tract infection, prolapse conditions and function of the bladder in the aged female hospital patients. Geront. clin. 7, I79.

Ursillo, R. C. (1967). Rationale for drug therapy in bladder dysfunction. In Neurogenic Bladder, ed. Boyarsky, S., pp. I87-189. Baltimore: Williams and Wilkins.

WaKin, K. G., Denton, C. \& Essex, H. E. (I954). Certain cardiovascular effects of vasopressin. Am. Heart f. 47, 77 .

Zimmermann, H. M. \& NetSky, M. G. (I950). The pathology of multiple sclerosis. Proc. Ass, nerv. Dis. 28, 27 I.

\title{
THE NEUROGENIC BLADDER IN THE NEWBORN INFANT
}

\author{
By J. H. Johnston, F.R.C.S. \\ Urological Surgeon, Alder Hey Children's Hospital, Liverpool
}

SINCE myelodysplasia associated with spina bifida most frequently affects the sacral segments of the cord and the cauda equina, the bladder lesion in affected infants tends to conform to the autonomous or lower motor neuron type. Only rarely, however, is the neural defect clear-cut. Often it is incomplete so that some afferent and efferent fibres remain intact; when the sensory elements are affected more severely than the motor, there may be some of the characteristics of the atonic bladder. In some instances the long tracts in the spinal cord are developmentally dysplastic above the overt spina bifida; in such cases there may be features of the automatic or upper motor neuron bladder.

Various classifications of the neurogenic bladder resulting from congenital myelodysplasia have been offered (Nash, I957; Roberts, I962; Smith, I965). Although details differ, each in general recognises two main types of case. In the first the bladder is flaccid, thin-walled and free of trabeculation. The urethral resistance is low so that the bladder does not become over-distended and manual expression is easily performed with more or less complete evacuation. The upper urinary tract is unlikely to be severely dilated and urinary infection is easily controlled. In the second type, the bladder is hypertrophied and heavily trabeculated. The urethral resistance is high so that expression is difficult and often incomplete and very commonly there is upper tract dilatation and severe urinary infection.

Whilst these two types represent the extremes of the spectrum, many cases fall in between or show some of the characteristics of each so that a variety of 